ARTE, CULTURA E IDENTIDADES

\title{
Transculturación narrativa en los cuentos de Carmen Lyra
}

\section{Narrative Transculturation in the Stories of Carmen Lyra Transculturação narrativa nos contos de Carmen Lyra}

\author{
María del Rocío García Rey \\ Poeta \\ Investigadora y docente \\ Universidad Nacional Autónoma de México \\ Recibido: 16/2/2016 - Aceptado: 15/4/2016 \\ DOI: http://dx.doi.org/10.15359/tdna.32-60.1
}

\section{Resumen}

Este artículo toma como eje algunos cuentos infantiles de Carmen Lyra, escritora costarricense, autora de Cuentos de mi tía Panchita (1922). Para exponer mis planteamientos extrapolaré algunos puntos presentados por Ángel Rama en su emblemático libro: Transculturación narrativa en América Latina. Consciente estoy de que la investigación de Rama no se trata de una obra en la que sea abordada la literatura infantil, sin embargo propongo que presenta elementos valiosos para explicar el juego cultural en el que se ve inmersa la reescritura y «traducción» de los cuentos de Lyra.

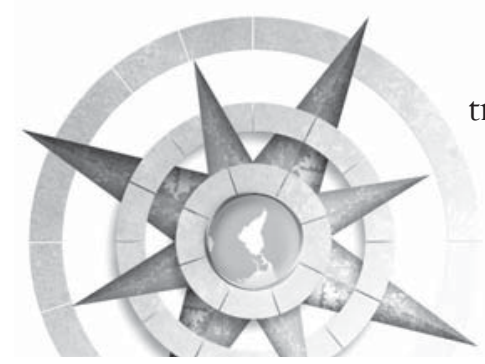

Palabras clave: literatura infantil costarricense, Carmen Lyra, Cuentos de mi tía Panchita, narratividad, transculturación, identidades, Nuestra América

\begin{abstract}
This work focuses on the children's stories of Carmen Lyra, the Costa Rican author of Cuentos de mi tía Panchita (Stories about my Aunt Panchita, 1922). Our approach is an extrapolation from several of the points made by Angel Rama's landmark work Narrative Transculturation in Latin America. While we are aware of the fact that Rama's work does not specifically address children's literature, it does present us with valuable elements to help explain the cultural game in which the re-writing and «translation» of Lyra's stories are
\end{abstract} immersed.

Keywords: Costa Rican children's literature, Carmen Lyra, Stories about my Aunt Panchita, [Cuentos de mi Tía Panchita], narrativity, transculturation, identities, Nuestra América. 


\section{Resumo}

Este artigo baseia-se em algumas das histórias de Carmen Lyra, escritor da Costa Rica, autor dos contos infantis Cuentos de mi tía Panchita [Histórias da minha tia Panchita] (1922). Na minha abordagem pretende extrapolarar alguns pontos apresentados por Angel Rama em seu emblemático livro Transculturación narrativa en América Latina [Transculturação narrativa na América Latina]. Estou ciente de que à literatura infantil não é abordada o trabalho de Rama; no entanto, mais fornece elementos valiosos para explicar o jogo cultural em que reescrever e «tradução» dos contos de Lyra está imerso.

Palavras chave: Literatura infantil costariquenha, Carmen Lyra, Histórias da minha tia Panchita, narratividade, transculturação, identidade, Nossa América

La literatura de nuestra autora se circunscribe en sus ambientes a los espacios rurales, ya se trate de los cuentos maravillosos o de los cuentos del tío Conejo. En el caso de los cuentos maravillosos hallamos lo que Rama nombra «temas culturales externos» (1982, p. 28), de ahí que los reyes, los castillos y los reinos sean propios de la diégesis. Ahora bien, lo interno es el aspecto folclórico con el que se complementan las narraciones. De acuerdo con Augusto Raúl Cortázar:

Son folklore los fenómenos culturales que se diferencian de otras expresiones también culturales, porque pueden ser específicamente caracterizadas como populares (propias de la cultura tradicional del folk, del pueblo), colectivizadas (socialmente vigentes en la comunidad), empíricas, funcionales, tradicionales, anónimos, regionales y transmitidos por medios no escritos ni institucionalizados (1964, p. 7).

Por ejemplo, en "La Flor del Olivar» (Lyra, 2010, pp. 125-130) la historia se desarrolla en un "país muy lejos de aquí», no es nombrado reino, pero hay reyes. Es precisamente al rey a quien, debido a su ceguera, se le aconseja que debe lavarse los ojos con el agua donde se haya puesto la flor del olivar. La historia transcurre con la acción del protagonista y héroe, que tiene que partir de la casa paterna. Ello en contraposición con sus hermanos, quienes juegan el papel de personajes antagónicos. Esta historia es presentada como original de Lyra, aunque existe una variación española titulada «Una canción muy triste». ${ }^{1}$

1 En Cuentos de príncipes y princesas. (1987). España: Altea. No se consigna el nombre del autor (en ninguno de los cuentos). Aunque en este cuento no se narra un fratricidio, el enlace con el cuento de Lyra está en que la flauta, al ser tocada, canta por voz del hermano muerto: «Hermano, hermano querido/, yo soy tu hermano perdido! / $\mathrm{Si}$ no vienes a encontrarme yo jamás te encontraré. /mis quejas repetiré/ sin dejar de lamentarme» (p. 28).

20 Transculturación narrativa en los cuentos de Carmen Lyra María del Rocío García Rey
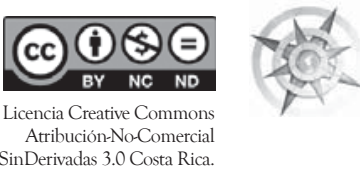
En la escritura de la costarricense encontramos como característica, en primer término, los giros dialectales. Leamos:

-Señor por amor de Dios deme algo de lo que lleva en sus alforjas; mi hijo está llorando de necesidad.

-iQue coma rayos, que coma centellas ese lloretas! (Lyra, 126)

La falta de solidaridad es repetida por el segundo hijo, quien además halla a su hermano «que lo entotorotó a que se quedara jugando su dinero» (Lyra, 127). El adjetivo lloretas y el verbo entotorotar son usados frecuentemente en los cuentos de nuestra autora. Lloretas significa 'llorón sin fuerzas', mientras que entotorotar tiene dos acepciones, despertar deseo sexual o simplemente despertar entusiasmo o inquietud (Ferrero, 2002).

La otra característica es la presencia de figuras divinas. En el caso del cuento citado el héroe (quien es el hijo menor) es premiado debido al apoyo ofrecido a los desposeídos.

Preguntó por qué lloraba el muchachito y la mujer le contestó que de hambre. Entonces el príncipe bajó de su caballo y buscó lo mejor que había en sus alforjas y se lo dio a la pordiosera. En su tacita de plata vació la leche que traía en una botella, con sus propias manos desmigó uno de los panes que su madre la reina había amasado, puso al niño en su regazo (Lyra 2010, p. 127).

Las palabras presentadas son apenas un ejemplo escueto, pues Cuentos de mi tía Panchita está basado en regionalismos y formas dialectales. Estoy de acuerdo con Cantillano cuando afirma: «[Lyra] usó la lengua campesina y coloquial para narrar sus cuentos cuya fuente en realidad fue el pueblo mismo» (Cantillano, 2006, p. 125).

Aunado al uso de las palabras, me parece muy importante considerar también la ruptura de estereotipos que la autora presenta, pues, por un lado, el príncipe no solo regala el alimento, lo prepara (tal acto echa por tierra el comportamiento «noble» de un príncipe, que pocas veces se ve en un cuento sirviendo y acunando a un niño), y, por otro, llama mayormente la atención la afirmación de que haya sido la reina, y no los sirvientes, quien haya amasado el pan. La reina entonces es como cualquier mujer dedicada a los menesteres del hogar. He aquí, pues, otro punto de diferenciación de la literatura infantil costarricense.

Por lo anterior, se puede decir que sí hay un modelo narrativo infantil, este como producto de la intersección entre expresiones narrativas y culturales. Es así que entra en juego

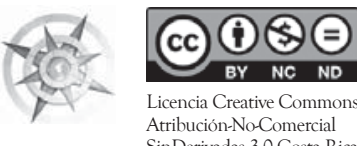

Transculturación narrativa en los cuentos de Carmen Lyra 
la cosmovisión para engendrar ciertos significados, mismos que son el producto del habla como «unificador estilístico» (Rama, 1982, p. 48). En este sentido, bien se puede extrapolar lo asentado por Darnton (2011) cuando afirma que lo esperado en la narración de un cuento no son comentarios sociales directos ni alegorías metafísicas, sino un estilo particular que comunica un ethos particular y una visión del mundo.

Si existe una fusión de temas culturales externos con el folclor, acaso se puede plantear como hipótesis la existencia de una literatura infantil que abre las puertas a temas de allende tierra, pero cuya expresión se halla en los rasgos que «recogen las formas idiomáticas dialectales» (Rama, p. 49) como marca unificadora e identitaria. Será con estas formas que significados y significantes queden imbuidos en el juego cultural mimetizado. Además no hay que olvidar la fusión imprescindible entre literatura y sociedad en la producción de la generación de Lyra. En este tenor cabe recordar la afirmación de Sarlo y Altamirano: «El escritor no opera como el productor del texto, sino como vehículo transparente y ocasional de los discursos que lo atraviesan» (1995, p. 65).

La llamada lengua culta no está presente en los cuentos infantiles de nuestra autora, de esta manera se legitima su afán de darles a los niños literatura propia de su tierra, lo que es posible interpretar como una brega por mantener una identidad mediante la enunciación (aus sagen) popular de Costa Rica.

En el caso de los escritores procedentes del regionalismo colocados en trance de transculturación, el léxico, la prosodia y la morfosintaxis de la lengua regional, apareció como el campo predilecto para prolongar los conceptos de originalidad y representatividad, solucionando al mismo tiempo unitariamente, tal como lo recomendaba la norma modernizadora, la composición literaria (Rama, 1982, p. 42).

Con base en lo anterior, se puede proponer el siguiente modelo:

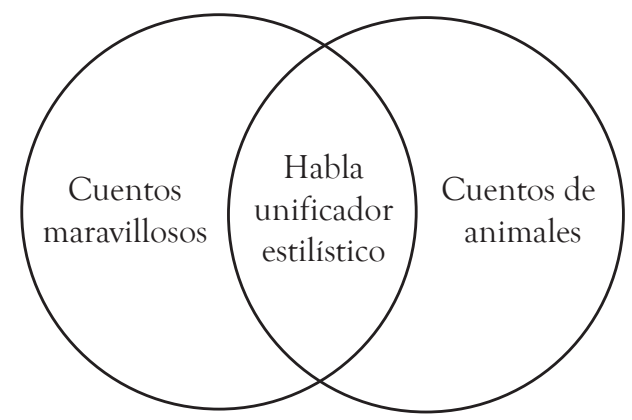

La incorporación de un corpus literario no latinoamericano implicó una transculturación narrativa que, a diferencia de otros momentos de la literatura para adultos, no dio paso a la discordancia lingüística (Rama, 1982), porque como he dicho la

22 Transculturación narrativa en los cuentos de Carmen Lyra María del Rocío García Rey
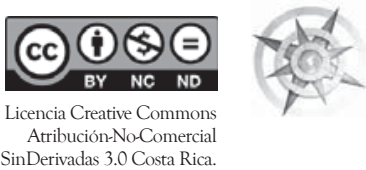
escritora y la narradora - la tía Panchita- se camuflan en una sola, de tal manera que es usada únicamente la lengua popular.

Cabe mencionar que el término transculturación narrativa es retomado por Ortiz, quien lo utiliza en contraposición al concepto aculturación, cuyo significado, para él, se vuelve unívoco (Rama, 1982).

Los giros dialectales unifican las expresiones de la narradora y de los personajes. Acaso este fenómeno nos pueda conducir a pensar en lo que Rama llama «un repliegue nacionalista» (Rama, p. 45), manifestado tanto en las formas de hablar como en la reinvención de los espacios costarricenses -en este caso sobre todo en cuentos del tío Conejo-. Se trata también, en términos de Rama, «de restablecer un contacto fecundo con las fuentes vivas, que son las inextinguibles de la invención mítica de todas las sociedades humanas, pero aun más alertas entre las sociedades rurales» (1982, pp. 52-53). Veamos un ejemplo de re-presentación mimética de las formas campesinas mostradas en «Tío Conejo comerciante».

Una vez tío Conejo cogió una cosecha que consistía en una fanega de maíz y otra de frijoles, y como era tan maldito, se puso a sacar de eso todo lo que pudiera.
Pues bueno, un miércoles muy de mañana se puso un gran sombrero de pita, se echó el chaquetón al hombro y cogió el camino. Llegó donde tía Cucaracha y tun, tun, tía Cucaracha que estaba tostando café, salió cobijándose con su pañuelo para no pasmarse (Lyra, 2010, pp. 189-190).

De acuerdo con Lara Figueroa, «los cuentos [del tío Conejo] permiten a los habitantes del campo y de los suburbios de las ciudades identificarse con su propia tierra» (s.f., p. 44).

Cabe aclarar que para Lyra el tío Conejo está emparentado con la figura de Uncle Remus, de Chandler Harris. Lo cierto es que los cuentos donde tío Conejo es el personaje principal nos dan una pauta para pensarlo como personaje unificador en la literatura popular infantil de varios países latinoamericanos. Algunos personajes icónicos devienen, entonces, impronta de unidad en cierto discurso literario para niños (en este caso se trata de países como México, Venezuela, Costa Rica, Cuba, Nicaragua, Colombia y Guatemala).

Con base en la figura del tío Conejo hallada en otros países latinoamericanos se puede suscribir que nos encontramos ante un mapa literario infantil del que Rama escribió. Así, no es para nada extraño que la figura de dicho personaje se encuentre en los

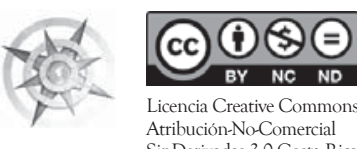

Transculturación narrativa en los cuentos de Carmen Lyra 
países que conformaron el conglomerado cultural y geográfico llamados por Darcy Ribeiro «Pueblos Testimonio (mesoamericanos y andinos)» (Ribeiro, citado por Rama, 1982, p. 59). Es por tratarse de pueblos-testimonio que el vehículo de transmisión y sobrevivencia de los cuentos de animales ha sido mediante la oralidad. La propia Lyra expresó:

Las siluetas cómicas que vagabundean sobre los labios carnosos de los negros y que Chandler Harris fijara en las páginas de un libro, se deslizan ejecutando sus piruetas que han esponjado en carcajadas tantas bocas de niños de piel morena y de piel blanca y fina. Bien que al llegar nosotros, nuestras abuelas transformaron estas siluetas: son ellas las de tío Conejo más ladina que de abogado y viejo; la de tía Zorra cuya proverbial astucia de nada le sirve ante el ingenioso conejillo y la de tío Conejo simplona y crédula como la de un campesino cándido en la ciudad (2010).

Hemos visto que Lyra presenta cuentos maravillosos y cuentos de animales; sin embargo es en los cuentos maravillosos en los cuales están presentes ciertas marcas que rompen con los estereotipos de los personajes de este género. Así, por ejemplo, en «El cotonudo» se desplaza el modelo del rey engreído y todopoderoso, es por ello que los consejos que este le da a su hija están relacionados con enseñarle que el poder verdadero no reside en la realeza, sino en Dios y en la Virgen. Leamos el pasaje:

Luego cogió a su hija menor por su cuenta y se puso a aconsejarla con muy buenas razones, porque este rey no era nada engreído: -Vea, hijita a nadie hay que hacerle ¡ché! en esta vida no hay que dejarse ir de bruces por las apariencias. ¡Quién quita le salga un marido nonis! Y en esta vida se hace ilusiones de que porque a veces se sienta en un trono más que los que se sientan en un banco. Pues nada de eso criatura, que solo Cristo es español y Mariquita señora... (Lyra, 2010, p. 46).

Es innegable que nuestra autora maneja una doble dinámica, pues en la representatividad de sus cuentos infantiles está, de manera concomitante, la diferencia con las versiones europeas que suelen ser las más difundidas - por lo menos en México-. ¿Cómo serían leídas estas versiones por el público europeo? La manera de traducir, reescribir y presentar las historias desplaza el modelo metropolitano de literatura infantil. Es posible, entonces, citar lo dicho por Rama: «El criterio de representatividad resurge en el periodo nacionalista y social que aproximadamente va de 1910 a 1940» (1982, p. 13). Tal criterio está presente en la escritura de Lyra,

24 Transculturación narrativa en los cuentos de Carmen Lyra María del Rocío García Rey

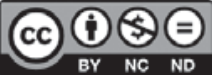

Licencia Creative Commons Atribución-No-Comercial SinDerivadas 3.0 Costa Rica. 
por ello ahora con más elementos se puede reafirmar que estamos ante cuentos maravillosos costarricenses que propalan un ethos y por ello una identidad particular en un periodo particular: la década de 1920.

\section{¿Literatura popular infantil?}

¿Quién decide qué es lo popular? El lugar de enunciación es la clave para entender cómo y cuándo han sido construidas las definiciones para tal concepto. Geneviève Bollème afirma: «Si el pueblo entra en una literatura o en la escritura, nunca será más que en virtud de una autorización, de una condescendencia» (1990, p. 203). Puedo estar de acuerdo con cierta dinámica de «autorización» dada al interior de los grupos letrados o de aquellos que nombran para sí su propia experiencia de lo (o en lo) popular. Empero, en el caso de Lyra, creo que más que una actitud de condescendencia, el rescate de lo popular mediante sus cuentos fue parte de un proyecto pedagógico y literario no aburguesado. $\mathrm{He}$ dicho que bregaba para ofrecerles a los niños historias propias de su tierra, y no «baratijas literarias», como ella las llamaba. No se trató en su caso de asumir una posición diletante ni una escritura «elevada», pero sí de comprometerse con la actividad letrada desde su posición de maestra.
Un hecho que no podemos pasar por alto, a propósito de la condescendencia y el rescate, es que la literatura infantil, así como la producida por Lyra, ha estado sometida -a su veza otros discursos de autoridad que determinan si es visible o no, si es difundida o no -en la misma América Latina-. Afirmo esto porque es sumamente evidente que los cuentos maravillosos conocidos, por ejemplo en México, son aquellos de los hermanos Grimm o de Perrault. Son cuentos que se toman como las versiones originales, olvidando que se trata también de versiones nacidas de los campesinos europeos; su origen entonces, es también popular.

En el caso de Lyra sus cuentos son escritos desde la periferia; cuyo significante y significado surgen a partir -en este caso sí- de la condescendencia del canon literario para dejarla entrever; afortunadamente tal escollo ha sido sorteado por varios autores. $\mathrm{Al}$ respecto, Nelly Richard «advierte (...) cómo la copia, que presenta simulaciones ya contenidas en la firma colonial, puede ir desviando el código europeo -tras la fingida obediencia hacia él-, basta la enunciación de mensajes alternativos» (Mateo, 1992, p. 45).

Lyra logró enunciar mediante su producción literaria tales mensajes alternativos, por ello en el principio 
de este apartado hablaba de la posibilidad de narrar acerca de lo popular desde un lugar de pertenencia. Esta afirmación se puede completar con el enunciado de Lombardi Satriani: «Los valores folklóricos señalan los límites de la universalidad, de los valores oficiales» (1975, p. 4). Es así que es posible reiterar que nuestra autora hace una renarración de aquellos considerados como cuentos universales. La universalidad se enfrenta, en este caso, a una ruptura con la hegemonía cultural.

Si para Bollème «el acto de escribir (...) es el momento fuerte de una tensión, porque escribir consiste en medirse, en enfrentar a una lengua establecida con el fin de tomar un lugar con sus propias palabras" (1990, p. 206), se puede decir que en el caso de nuestra autora el lenguaje vernáculo no sufre una tensión antagónica con el lenguaje culto, porque al parecer lo que predominaba en Costa Rica era precisamente este lenguaje «propio del pueblo».

Por ello Lyra narró para los niños, utilizando los giros dialectales que eran parte de la cotidianidad de estos pequeños lectores. De hecho si nos atenemos a la definición que Lara Figueroa proporciona acerca del cuento popular, definido como «[una] obra literaria anónima, tradicional y oral, sin localización en el tiempo y en el espacio, que narra sucesos ficticios y que tiene generalmente carácter estético» (s.f., p. 39), cabe decir que los cuentos de la costarricense -pese a que son transmitidos mediante la escritura- conservan el anonimato de sus contadoras originales, pues bien se sabe que la tía Panchita no fue la creadora de sus historias, los sucesos que narra son, efectivamente, ficticios y narrados una vez que ella los escuchó en algún lugar. Se trata de historias contadas mediante un lenguaje asequible. De esta manera, por ejemplo, hay que prestar atención en lo que se refiere a los sustantivos y adjetivos. Tal como lo señala Cantillano: «En los cuentos de mi tía Panchita, como en la lengua hablada del país, los sustantivos, los adjetivos y hasta los adverbios, presentan gran riqueza de formas diminutivas y comparativas, comunicando a las narraciones gran variedad de matices (2006, p. 131).

El regionalismo queda emparentado así con los elementos del folclor costarricense, de tal manera que los dos se intersecaron para dar vida a la enunciación ficticia representada por los cuentos. Si Propp ha planteado que el motivo tiene su origen en un rito, yo digo que tanto rito como motivo son un desdoblamiento de la intersección mencionada. En el caso de «El pájaro Dulce Encanto», el regionalismo es

26 Transculturación narrativa en los cuentos de Carmen Lyra María del Rocío García Rey
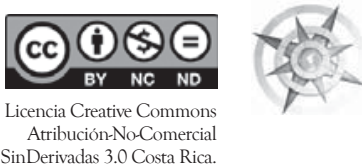
presentado por la autora mediante la connotación apenas perceptible de emblemáticos elementos de la naturaleza tica: se trata de una comparación de «rubíes tamaño una bellota de café» (Lyra, 2010, p. 146).

El motivo de «El pájaro Dulce Encanto» es muy cercano al de "La Flor del Olivar"; en ambas historias el rey está ciego; pero en este caso no es el azar el que introduce al personaje que se encargará de dar solución al problema. En este cuento una bruja y curandera es llamada al palacio. Podríamos decir que se trata de un cuento maravilloso que adquiere aún más encanto (parafraseando a Cantillano), es la incorporación de un refrán:

Al salir el mayor de la ciudad, vio un grupo de gente a la entrada de la iglesia - ¿Y adónde vas Vicente? Al ruido de la gente- se acercó a ver qué era y se encontró con un muerto tirado en las gradas y uno de los del grupo le contó que lo habían dejado allí porque no tenían con qué enterrarlo, y que el padre no quería cantarle unos responsos si no había quién le pagara. (Lyra, 2010, p. 144).

De los tres príncipes es al menor a quien «se le mueve el corazón»y por ello paga para que el difunto pueda ser enterrado dignamente. Se trata, de acuerdo a la morfología de Propp, de «el muerto agradecido», pues es porque el héroe pagó para que pudiera descansar en paz que el difunto le enseñará cómo hallar al pájaro Dulce Encanto. Esto, que es propio de los cuentos maravillosos, se puede conectar con el carácter mimético en el que está presente el rito y el mito. El primero tiene que ver con la ceremonia que en la mayoría de las culturas se lleva a cabo para darle sepultura a los muertos; el mito, por su parte, acredita la creencia de que si el rito no se lleva a cabo, el difunto no podrá descansar. Esta creencia popular nos hace suscribir que «el motivo tiene su origen en un rito» (Propp, 2008, p. 28).

La escritura de este cuento tampoco es ajena a ciertos momentos de humor, en los que la autora incorpora giros costarricenses. La luz (que es el alma del difunto agradecido) le llama la atención al príncipe: «iIdiay, hombré, ya olvidaste a lo que venías? A ver si vas al cuarto que sigue, que es el comedor y te alcanzas cuanta mesa y silla encontrés» (Lyra, 2010, p. 146). Motivo, rito y mito son entonces un trinomio cuya narración queda emparentada tanto al habla como a la creencia popular (en este caso en torno a la muerte).

Los cuentos populares en Lyra, además de lo expresado, adquieren tal adjetivo porque están formados de lo que Rama llama corpus de mitos y leyendas recogidas. Empero, si para

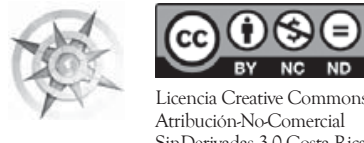

Transculturación narrativa en los cuentos de Carmen Lyra 
el mismo autor se ha preferido -bajo el paradigma de la ciudad letradaotro corpus literario (Rama, 1982), cabe decir que Lyra articuló una praxis que no desdeñaba el rescate que otras mujeres, sin ser letradas, habían hecho de las historias que ella reescribía. En sus palabras:

¡Qué sugestiones tan intensas e inefables despertaban en nuestras imaginaciones infantiles, las palabras de sus cuentos, muchas de las cuales fueron fabricadas de un modo incomprensible para la Gramática, y que nada decían a las mentes de personas entradas en años y en estudios! (Rubio, en Lyra, 2010).

Si la gramática culta no es el eje de la enunciación popular, sí lo son las historias y la manera de contarlas. Con la costarricense se le dio continuidad histórica a las formas dialectales, mismas que sirvieron para entrar en contacto con los infantes. Por ello reitero que en este caso no se trató de una condescendencia ni de una ruptura drástica con la ciudad letrada. En Lyra hay un convencimiento de que sus cuentos fueron recreados en América:

¿Qué muerta imaginación nacida en América los entretejió, cogiendo briznas de aquí y de allá, robando pajillas de añejos cuentos creados en el Viejo Mundo? Ella (La Tía Panchita) les ponía la gracia de su palabra y de su gesto que se perdió con su vida (Rubio, en Lyra, 2010).

Lyra no necesitó proclamarse vanguardista para ser considerada como parte del grupo que renovó las letras costarricenses y, por qué no, latinoamericanas.

La historia de la literatura costarricense ha tenido como eje central la configuración y explicación de lo que significa la costarriqueñidad, como esa esencia de lo que caracteriza el «alma» del ser costarricense, es decir, la manifestación propia de rasgos inherentes, particulares que nos permiten conocer lo que define al costarricense en general, y lo hace diferente a otros grupos (Alvarado, 2009, p. 15).

La literatura popular infantil, en este caso, es fruto de un convencimiento para forjar una identidad mediante historias lúdicas y costumbristas -en el caso de los cuentos del tío Conejoy costumbristas y maravillosas -en el caso de los cuentos maravillosos-. El aspecto lúdico originado de lo oral y lo popular aparece en los finales de varios cuentos de nuestra autora. Es con uno de ellos que yo también cierro este trabajo. "Y me meto por un huequito y me salgo por otro, para que ustedes me cuenten otro».

28 Transculturación narrativa en los cuentos de Carmen Lyra María del Rocío García Rey
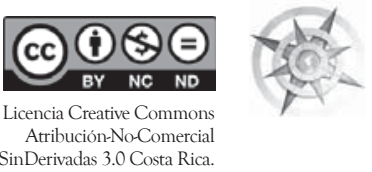


\section{Referencias}

Altamirano, C. y Sarlo, B. (1995). Literatura/ Sociedad. Buenos Aires: Hachette.

Alvarado, G. (2009). Literatura e identidad costarricense. Costa Rica: EUNED.

Bollème, G. (1990). El pueblo por escrito, significados de lo "popular» (trad. Rosa Cusminsky de Cendrero). México: Grijalbo/CONACULTA.

Cantillano, O. (2006). Los cuentos de mi tía Panchita de Carmen Lyra. Costa Rica: EUNED.

Cortázar, A. (1964). Folklore y literatura. Argentina: EUDEBA.

Darnton, R. (2011). La gran matanza de los gatos y otros episodios en la historia de la cultura francesa (trad. Carlos Valdés). México: FCE.

Ferrero, L. (2002). Mil y tantos tiquismos (costarricensismos). Recuperado de https://books.google.com.mx/ books?isbn=9968311812

Lara, C. (s.f.). Los cuentos de nunca acabar en la tradición oral guatemalteca. Recuperado de http://www.lacult.unesco.org/ docc/oralidad_10_39-50-los-cuentosde-nunca-acabar.pdf

Lyra, C. (2010). Cuentos de mi tía Panchita. San José: Editorial Costa Rica.

Lombardi Satrini, L. (1975). «Folklore y cultura popular» en Los libros, (enero - febrero). PFD. Recuperado de http://documents. $\mathrm{mx} /$ documents/satriani-lombardifolklore-y-cultura-popular.html

Mateo, M. (29 de noviembre, 1992). Postmodernidad y literatura en América Latina. La Jornada Semanal, n. ${ }^{\circ} 181$, p. 45.

Propp, V. (2008). Raíces históricas del cuento. México: Colofón.

Rama, A. (1982). Transculturación narrativa en América Latina. México: Siglo XXI. 